\title{
Opções Para Lidar Com as Causas de Desflorestamento no Norte de Moçambique: Caso Dos Distritos de Majune e Marrupa
}

\author{
Jerónimo Victor Teixeira* \\ Mozambique \\ *Corresponding Author: Jerónimo Victor Teixeira, Mozambique

\begin{abstract}
The purpose of this study is to suggest options to address the causes of deforestation, which are recurrent, in the districts of Majune and Marrupa, in the Northern Province of Niassa, in Mozambique. The research is of a qualitative scope, in the case study modality, based on the theoretical model of sustainable development that dominates the dictates of the 2030 agenda. The results indicate weaknesses in the application of the forest sector legislation in the study area, which translate in conflicts between the local population and forest authorities, as well as with licensed forest operators, due to the alleged constancy of irregularities in the inclusion of local communities in the decision-making process on the ways of using and using forests and other natural resources in the area under its jurisdiction. This study proposes for the study area the introduction of payment for environmental services, the use of medicinal plants and suggests three innovative scenarios, hypothetically applicable to the management of the territory concerned, taking into account the usual lifestyle of local communities. The selection of the scenario to be applied is sent to the actors interested in the sustainable management of forests in Mozambique and in other similar realities at the international level.
\end{abstract}

Keywords: Options, deforestation, causes, scenarios, sustainable development, Mozambique

\section{INTRODUÇÃO}

As florestas são cruciais para enfrentar inúmeros imperativos de desenvolvimento sustentável, desde a erradicação da pobreza à segurança alimentar, desde a mitigação e adaptação às mudanças climáticas à redução do risco de desastres naturais (ONU, 2014, WRI, 2014).

A perda e degradação das florestas constituem um enorme problema ambiental da actualidade. Embora as taxas de desflorestação tenham registado um decréscimo, em algumas regiões do Planeta, os ecossistemas florestais ainda estão sob grande ameaça. Dados divulgados pelo World Resources Institute (WRI) revelam que 30 por cento da cobertura florestal global tem sido destruída, enquanto outros 20 por cento está degradada. Grande parte da restante percentagem encontra-se fragmentada, restando apenas cerca de 15 por cento de florestas intactas (WRI, 2014).

Conjuntamente com a América Latina, África é o continente que regista as maiores perdas de floresta (FAO 2010a). De acordo com Kissinger et.al. (2012), as acções imediatas, que causam impactes directos na floresta, os chamados impactes directos, incluem: (i) agricultura (comercial e de subsistência); (ii) infra-estruturas; (iii) extracção de madeira para a comercialização; iv) mineração e, v) expansão urbana. Os factores directos da degradação da floresta incluem o abate de árvores, as queimadas descontroladas, a pastagem de gado, a exploração de madeira, a colecta de lenha e a produção de carvão.

Adicionalmente, Mustalahti (2011) aponta três problemas reais relacionados com a gestão florestal sustentável, em África, nomeadamente:(i) a falta de incentivos para a população local se capacitar na participação activa no controlo e gestão de recursos naturais;(ii) uma atitude conservadora entre os silvicultores e políticos, que se assumem como únicos na tomada de decisão, mesmo reconhecendo que a floresta precisa de ser protegida pela população local;(iii) a falta de incentivos e motivação necessários para as administrações distritais poderem promover os direitos locais e a capacitação das pessoas. 
Observações preliminares nos distritos de Majune e Marrupa, na Província Setentrional de Niassa, em Moçambique, cujas condições naturais e características socioeconómicas são semelhantes, indicam a persistência de acções de desflorestamento cujas causas já foram estudadas no passado em outras regiões do país por A Salomão, e F Matose, 2007; A Sitoe, A Salomão, S Wertz-Kanounnikoff 2012, entre outros.

$\mathrm{Na}$ essência, os referidos estudos de natureza mista revelam que pouco se sabe sobre as mudanças de cobertura florestal, em Moçambique, mas defendem que o desflorestamento no país, em geral, é devido à prática da agricultura e à utilização da energia lenhosa, aliada à insuficiência de alternativas de sustento por parte das comunidades locais, cuja sobrevivência depende dos recursos florestais. Esta circunstância constitui enorme desafio para os tomadores de decisões na viabilização das acções antrópicas que permitam a necessária promoção da utilização dos recursos naturais de maneira sustentável, à luz da legislação do ambiente em vigor no país em geral, incluindo na regulamentação sobre a gestão do território e das florestas em particular.

Apesar das constatações anteriormente expressas, ainda não existem estudos conclusivos que indiquem medidas exequíveis para fazer frente aos constrangimentos identificados na gestão de florestas em Moçambique em geral e na área de estudo em particular. Com efeito, esta é a primeira pesquisa a propor opções inovadoras respeitando as características e hábitos enraizados no seio das comunidades autóctones, tendo em vista colmatar as causas de desflorestamento, como contributo para o sucesso na tomada de decisões por parte de potenciais agentes com interesse na gestão sustentável das florestas no contexto moçambicano.

\section{Metodologia}

A presente pesquisa foi realizada com base na metodologia qualitativa, na modalidade de estudo de caso nos distritos de Majune e Marrupa. A recolha de dados foi feita com recurso às técnicas de observação directa, análise documental e entrevistas com 16 pessoas chave, que foram seleccionadas intencionalmente ao nível dos governos provincial, distrital e de Posto Administrativo, os utilizadores locais das florestas, ou seja, os operadores com concessões e/ou licenças simples; os carvoeiros, lenhadores, agricultores e seus respectivos líderes locais.

Foram igualmente entrevistados seis representantes das organizações não-governamentais que operam no ramo florestal na área de estudo, nomeadamente: a) World Wildlife Fund for Nature "Fundo Mundial para a Natureza" (WWF). Esta Organização está sediada na Província de Niassa, concretamente nas imediações do Lago Niassa; b) A MALONDA - uma entidade privada moçambicana sem fins lucrativos e de utilidade pública, criada em 2005 e opera na Província de Niassa. O Programa Malonda resulta de um acordo de cooperação entre o Governo de Moçambique e o Governo Sueco assinado em 1997 e através da Resolução n ${ }^{\circ} 3$ de Conselho de Ministros, de 25 de Janeiro de 2005, para a promoção e facilitação do desenvolvimento do sector privado em Niassa.

\section{RESUltados E Discussão}

$\mathrm{Na}$ área de estudo foi possível identificar as seguintes características dominantes: a) baixa densidade populacional (3 a 4 habitantes $/ \mathrm{km}^{2}$ ); b) mudanças constantes de residência da população local, nesta pesquisa apelidadas de "nomadismo", que será abordado mais adiante; c) baixo nível de escolaridade directamente proporcional à idade em ambos os sexos, com maior expressão nas mulheres; d) a prática de agricultura itinerante; e) a multifuncionalidade das florestas; f) a floresta é único recurso para o sustento da população local.

Uma vez que em Moçambique as comunidades locais são compostas por um espectro diverso: género, idade, religião, riqueza, grupo e classe social, cultura, interesse pessoal ou colectivo sobre o uso dos recursos (Couple et al. 2002; Fabricius et al. 2004; Jones \& Murphree, 2004; Katerere, 2002; Salomão, 2002; Shackleton \& Shackleton, 2004; Turner \& Meer, 2001), torna-se urgente o envolvimento das comunidades locais através do incentivo à adopção de atitudes sustentáveis com enfoques localizados, com o objectivo de salvar os recursos florestais em benefício das actuais e das futuras gerações.

Tendo em consideração os principais factores de mudança do coberto florestal e as características dos utilizadores das florestas na área de estudo, apresentam-se, de seguida, algumas opções para lidar com as causas do desflorestamento, incluindo-as no contexto da necessária participação das comunidades 
locais, cujo interesse se fundamenta no facto de que elas têm uma relação histórica com as suas terras e, regra geral, descendem dos habitantes oriundos dessas mesmas terras onde durante muitas gerações, elas desenvolveram um conhecimento tradicional dos seus recursos naturais e do seu ambiente, acumulando experiências de diferentes formas de gestão dos recursos naturais que têm implicações importantes para essas comunidades.

Entre as alternativas para promover a sustentabilidade na utilização das florestas da área de estudo, a pesquisa considera aplicável o pagamento de Serviços Ambientais para promover melhorias na relação ser humano/recursos naturais colmatar as insuficiências enfrentadas pelas comunidades locais.

O referido pagamento seria uma recompensa financeira para os usuários do solo que proporcionam serviços ambientais, conservando os sistemas naturais. Este pagamento é percebido como uma estratégia para fomentar a gestão integrada do solo, da água e dos recursos vivos para promover a sua conservação e uso sustentável de forma equitativa (CBD 1992).

Os benefícios do Pagamento por Serviço Ambiental às comunidades da área de estudo poderiam ocorrer a curto e a longo prazo. A curto prazo incluir-se-ia o aumento da renda em dinheiro para o consumo ou investimento; a expansão da experiência, com actividades externas de negócios relacionados ao Pagamento por Serviços Ambientais, através de operações económicas e das interacções com intermediários relevantes ao mesmo.

Estes estímulos promoveriam, igualmente, o conhecimento das práticas de uso sustentável dos recursos naturais através de assistência técnica e de formação associada à implementação do acordo. A longo prazo, os benefícios consistiriam na melhoria da resistência dos ecossistemas locais e do seu fluxo de serviços, além de representarem um potencial para o aumento da produtividade do solo devido ao investimento em serviços ambientais (Forest Trends, Grupo Katoomba, e PNUMA, 2008).

Entretanto, algumas experiências internacionais mostram que esse modelo não é uma panaceia para o alívio à pobreza, devido a problemas relacionados com a capacidade dos grupos mais pobres de aceder a estes esquemas e a larga escala dos projectos de pagamentos por Serviços Ambientais, entre outros (Pagiola et.al. 2005, Wunder,2008).

Refira-se que tem sido levantada uma série de limitações que inibem a aplicação generalizada dos pagamentos por serviços ambientais nas comunidades rurais, tais como: o acesso limitado às informações sobre pagamentos de serviços de ecossistema, a economia de uso da terra, potenciais compradores de Pagamento por Serviços Ambientais, falta de financiamento para a avaliação dos Pagamentos por Serviços Ambientais, capital inicial e custos de transacção, limitada capacidade de negociação para influenciar, formar ou aplicar regras e contratos, resolver disputas, ou para tratar de queixas, especialmente com os agentes do sector privado (Forest Trends, Grupo Katoomba, e PNUMA, 2008).

Os autores apontam ainda dificuldades relacionadas com a base patrimonial limitada para absorver riscos, investir tempo e recursos na gestão, nos períodos de menor retorno ou em maiores requisitos trabalhistas, a organização limitada e incapaz de agregar ofertas de serviços necessários para atrair um leque de compradores, a falta de instituições intermediárias eficientes para reduzir os custos de transacção, as prioridades locais para satisfazer as necessidades dos serviços ambientais, entre outros.

Apesar de se apontarem inúmeras limitações, importa considerar a opinião dos autores que defendem que o Pagamento por Serviços Ambientais pode ser viável, desde que seja moldado de acordo com o contexto em que ele esteja situado, tendo em atenção que as oportunidades devam ser cuidadosamente elaboradas, criadas e monitoradas para assegurar que os benefícios sejam voltados para as pessoas que mais necessitam desses benefícios.

Outra opção a considerar, para lidar com as causas do desflorestamento, com ganhos significativos para as comunidades locais, seria a aposta na identificação, protecção, extracção e comercialização de derivados de plantas medicinais que são abundantes na área de estudo, como incentivo à sua conservação. Todavia, esta opção requer uma estratégia própria que possa ser usada para incentivar as comunidades a participarem na protecção das florestas e fazerem o aproveitamento dessas plantas com apoio de especialistas botânicos para a posterior colocação no mercado farmacêutico apropriado.

É de destacar que muitas espécies de flora de Moçambique, descritas como medicinais na bibliografia estrangeira especializada, estão na composição de medicamentos tradicionais moçambicanos idênticos 
ou de formulações diferenciadas, que ainda não se tem informação suficiente (Jansen \& Mendes, 1983).

Um aspecto a considerar na abordagem sobre a utilização de plantas medicinais, em Moçambique, é que o conhecimento e o exercício da medicina tradicional com recurso a vegetais e animais, em geral, nunca foram acessíveis a todos os indivíduos, mantendo-se na posse de «eleitos» que detêm os segredos aprendidos e desenvolvidos para oportunamente os ensinarem geralmente a adolescentes ou jovens, de sua exclusiva escolha.

Apesar de aparentemente irrelevante, há igualmente uma tendência, um pouco por todo o país, que constitui obstáculos à divulgação dos conhecimentos sobre o uso medicinal das plantas que são abundantes nas florestas moçambicanas, associada à dificuldade de acesso ao conhecimento da aplicabilidade das plantas medicinais para fins terapêuticos no seio das comunidades locais.

A atitude anteriormente referida acontece, provavelmente, porque além do uso dos conhecimentos de terapia, os especialistas nesta matéria (os curandeiros) que em Moçambique são conhecidos por "médicos tradicionais" manipulam também as crenças e superstições populares prevalecentes para fazerem valorizar os seus dons e méritos e exercerem cada vez maior domínio, inferiorizando os utilizadores que se limitam a aplicar aqueles conhecimentos (Jansen \& Mendes, 1983).

Considerando que o desflorestamento e degradação florestal reflectem a falta de sistemas de vida viáveis nas áreas rurais em Moçambique em geral e na área de estudo em particular, torna-se oportuno definir cenários para cada situação/problema de sobrevivência, respeitando as tradições e hábitos locais.

De acordo com Porter (1996), um cenário é uma visão internamente consistente da estrutura futura de um sector. É baseado num conjunto de suposições plausíveis sobre as incertezas importantes que, de alguma forma, poderiam influenciar a estrutura sectorial. Por seu turno, Godet, et.al. (2008) conceitua cenário como o conjunto formado pela descrição de uma situação futura e do encaminhamento dos acontecimentos que possibilitem passar da situação originária para a futura.

Concordando com a conceituação apresentada anteriormente e para atender as características singulares da área de estudo, a presente pesquisa avança três cenários, vistos como ferramentas de apoio à tomada de decisão sobre os assentamentos e/ou reassentamentos da população, para assegurar a satisfação das suas necessidades e garantir a utilização e conservação das florestas, incluindo-as no contexto de futuras formas de gestão, com implicações importantes para as comunidades locais e cuja adopção ficará ao critério dos decisores:

i) Cenário de permanência do sistema de gestão do território;

ii) Cenário de mudança controlada e,

iii) Cenário de mudança por ruptura.

Após a breve apresentação, passa-se à explicação da aplicabilidade dos contornos e implicações de cada um dos cenários propostos.

\section{i) Cenário de Permanência do Sistema de Gestão do Território}

No contexto da área de estudo, as acções ao nível local, aspirando conseguir melhores formas de gestão florestal, deveriam incluir incentivos e medidas específicas, que permitissem fomentar a conservação de florestas, tais como: actividades de geração de receitas alternativas e promoção da utilização de energias alternativas para conter a pressão sobre a floresta, na recolha de lenha e na produção de carvão vegetal.

O enfoque deste cenário está orientado para a manutenção criteriosa das práticas habituais dos habitantes da área de estudo, com acções concentradas na preservação da floresta, numa óptica da sustentabilidade. Esta abordagem reconhece que apesar de a legislação moçambicana para o sector das florestas ser rica em conteúdo, a sua aplicação prática tem sido pouco eficiente no que concerne à participação das comunidades locais na tomada de decisões relevantes, cujos impactos afectam as suas condições de existência.

A observação e as entrevistas realizadas com as comunidades locais confirmaram anteriores estudos feitos por Amaral (1990), Junod (1973), citados por Ombe e Fungulane (1996) sobre algumas formas 
tradicionais de conservação da Natureza em Moçambique pré-colonial, que apontam aspectos relevantes, indicadores da preocupação da população nativa em manter um equilíbrio entre as comunidades locais e a natureza.

Tal preocupação expressa-se através de ritos, de celebrações e de práticas mágico-religiosas que foram testemunhadas durante o trabalho de campo levado a cabo para esta pesquisa, demonstrando-se a sua actualidade e relevância em todos os distritos que fizeram parte deste estudo. Por exemplo, a prevalência da agricultura itinerante, os ritos de iniciação de jovens que são realizados nas florestas, os cultos aos antepassados que ainda vigoram nas chamadas florestas sagradas e nas montanhas, são alguns dos aspectos que outrora contribuíram para a manutenção do equilíbrio ecológico.

Apesar de a História humana considerar o nomadismo como o estilo de vida dos primeiros homens sobre a Terra e entretanto, esta forma de vida ter sido abandonada por volta de 10 mil anos atrás, quando o ser humano descobriu a agricultura, ainda é possível encontrar, em Moçambique, alguns aspectos semelhantes ao nomadismo, principalmente na área de estudo. Sabe-se que o nomadismo que caracteriza as comunidades da área de estudo é incompatível com a melhoria de infra-estruturas sociais básicas, tais como, as de saúde e educação, bem como o abastecimento de água, a habitação e outros serviços indispensáveis para garantir um nível de vida aceitável, como por exemplo, o fornecimento da energia eléctrica, a disponibilização dos meios de transporte e respectivas vias, entre outros.

Numa abordagem dirigida à manutenção do sistema tradicional, torna-se impraticável a disponibilização dos serviços básicos às comunidades desta área, pois não seria viável, por exemplo, a edificação de infra-estruturas convencionais mas, em alternativa, seria razoável o recurso a infraestruturas móveis, digo escolas e postos de saúde assim como habitaçõespré-fabricadas e de baixo custo, com recurso amateriais que possam ser reutilizados em caso de mudança de residência por parte dos habitantes, acompanhando-os para os novos locais que futuramente viessem a ser escolhidos para habitação.

Nesta mesma abordagem, o abastecimento em água potável deveria ser garantido através duma distribuição diária feita com recurso a um camião-cisterna, em locais que seriam previamente identificados e seleccionados pelas próprias comunidades em cada aldeia ou povoado.

A viabilização da alternativa anteriormente proposta, seria assegurada, com o apoio dos recursos do Estado, a exemplo do fundo de desenvolvimento local (FDL) vulgo sete milhões de meticais, que num passado recente eram disponibilizados anualmente a todos os distritos do País para financiar projectos individuais e colectivos, em benefício das comunidades locais.Para tal, seria promovida assistência às comunidades nómadas na abertura e manutenção das vias de acesso não asfaltadas e sem necessidade de eliminar definitivamente toda a vegetação natural nos troços percorridos pelas vias provisórias. Esta alternativa implicaria que cada aldeia ou povoado possuísse no mínimo uma viatura operacional e um reservatório móvel de água para esse fim.

\section{ii) Cenário de Mudança Controlada}

Este segundo cenário é baseado na alteração do sistema tradicional de gestão do território por introdução de uma abordagem nova, mas de forma controlada, quer pela administração, quer pelas comunidades locais.

Considerando que as intervenções a nível local precisam se adequar às condições ditas, locais, mas ainda assim consideradas dentro do contexto nacional e ciente de que qualquer abordagem nova sobre os modos de vida numa comunidade é inevitavelmente susceptível a certa resistência, a adopção deste cenário implicaria acautelar alguns aspectos como forma de aconstituir freio a prováveis actos de resistência à mudança.

$\mathrm{Na}$ prossecução deste cenário, sempre que se pretenda aplicar desincentivos para desencorajar o desflorestamento, tais como impostos, multas, limites à produção, zoneamento, que requeiram algum nível de execução, deverá se incluir a participação de membros influentes da comunidade local, reforçando a sua capacitação e garantindo benefícios que preparem o terreno rumo a uma gestão florestal eficaz. 
Acredita-se que, para evitar desarmonia na introdução de mudanças na gestão das florestas, qualquer acção com implicações no seio da população local deveria partir duma negociação com os residentes. Nessa negociação deveria sempre considerar-se as convicções e aspectos tradicionalmente considerados relevantes por parte dos residentes, pese embora a terra e todos os recursos naturais em Moçambique sejam pertença do Estado.

Conforme se constatou nas entrevistas, durante a realização do trabalho de campo, a exclusão da população residente na tomada de decisões de atribuição das licenças aos operadores florestais, externos à área de estudo, nacionais e estrangeiros, inúmeras vezes tem ocasionado situações conflituosas entre as autoridades florestais e os utilizadores locais das florestas.

Ficou igualmente evidenciado que as intervenções dos agentes externos no uso dos recursos florestais da área de estudo, como é o caso das concessões florestais e coutadas, têm gerado conflitos entre estes operadores com os residentes, devido à introdução de normas e regulamentos que impedem as práticas usuais no seio das comunidades locais que sempre reclamam os seus antigos espaços de caça, pesca, cultos mágico-religiosos, a recolha de lenha, de plantas medicinais e demais produtos florestais incluindo a produção do carvão vegetal.

A falta de inclusão das comunidades locais no processo de planificação das intervenções a serem levadas a cabo no território, pode muitas vezes resultar no fracasso, como no exemplo que se observou no Distrito de Marrupa, onde o Governo investiu na construção de uma escola com recurso ao material convencional; num posto de saúde e num fontenário para o abastecimento de água na Localidade de Messenguesse.

Pouco tempo após a disponibilização dos referidos serviços e dos respectivos funcionários públicos, a população das aldeias que deveria ser servida por tais serviços e infra-estruturas,abandonou aquelas aldeias e foi residir para outro espaço que considerou possuir condições adequadas para a sua fixação, na floresta, desvalorizando o investimento estatal na área que antes lhes acomodou, fazendo valer os seus hábitos e tradições.

\section{iii) Cenário de mudança por ruptura}

Atendendo à existência de conflitos de interesse na utilização das florestas nativas e de uso múltiplo, na área de estudo, não se deve crer que toda ou pelo menos a maior parte da população esteja em condições de compreender o valor e conscientemente colabore na defesa generalizada das florestas. Deve-se, sim, fazer tudo o que estiver ao alcance para a defesa das florestas nativas do País.

O presente cenário propõe uma alteração substancial do sistema tradicional de gestão do território pelas comunidades locais, mesmo que com benefício/contrapartidas directas negociadas. A operacionalização desta abordagem pressupõe que se acautelem dois aspectos fundamentais:

a) Primeiro, dever-se-á incrementar os programas e projectos que promovam a alfabetização das comunidades e seus líderes, uma vez que o analfabetismo nesta área é directamente proporcional à idade dos habitantes. Deve-se ainda promover uma capacitação contínua e permanente destas comunidades para que a médio e longo prazo possam beneficiar da informação disponível sobre as boas práticas na utilização dos recursos naturais, cuja contrapartida é uma série de benefícios para as próprias comunidades no presente assim como para as gerações futuras;

b) Segundo, dever-se-á fomentar e acelerar a requalificação e delimitação das áreas florestais, acompanhada de uma promoção do ordenamento das mesmas, com a materialização de mecanismos intransigentes de ocupação ordenada e de acordo com os padrões considerados adequados.

Para assegurar a exequibilidade das medidas antes mencionadas, as comunidades seriam compensadas financeiramente ao desocuparem as terras que antes ocupavam, com recurso ao fundo de desenvolvimento local que é disponibilizado anualmente aos distritos pelo governo central. Além deste incentivo, as comunidades locais teriam o benefício de serem servidas por infra-estruturas convencionais e diversos serviços sociais tais como os de saúde e educação.

A adopção deste cenário exige também a introdução de outras alternativas de subsistência que possam proporcionar sustento independente da exploração e do uso intensivo dos recursos da floresta que actualmente não é feita de maneira sustentável. Por exemplo, poderia se incentivar e capacitar as 
comunidades para se empenharem em projectos de apicultura e aquacultura, nas localidades onde as condições fossem favoráveis para a prática dessas actividades.

\section{Conclusões}

Reconhecendo a dependência em relação à floresta por parte dos habitantes dos distritos de Majune e Marrupa, urge adoptar-se medidas inovadoras para garantir a manutenção dos recursos florestais sem, contudo, pôr em causa a sobrevivência das comunidades locais que têm uma relação histórica com estes recursos.

Actualmente, a fome e a urgência na satisfação das necessidades básicas não permitem que as comunidades locais da área de estudo tenham um horizonte de planificação e uso dos recursos naturais a longo prazo.

Os cenários propostos nesta pesquisa podem-se aplicar às comunidades que praticam o nomadismo, mas não a outras. Além de garantirem a participação na gestão florestal,estes cenários podem promover a segurança alimentar e melhoria da dieta dos residentes por um lado, reduzindo a pressão exercida sobre as florestas por outro.

A adopção de um dos cenários ou a combinação destes deve ser decidida tendo em conta que a utilização das florestas na área de estudo é essencial para a sobrevivência das comunidades locais assim como para a geração de rendimento nacional a longo prazo.

Recomenda-se investigação a longo prazo, sobre fontes alternativas de rendimento, com enfoque sobre os produtos florestais não-madeireiros e seus derivados, especialmente para as comunidades cuja sobrevivência depende exclusivamente da utilização das florestas.

É sobretudo importante advertir para a realização de estudos multidisciplinares, a longo prazo, sobre as dinâmicas e os efeitos do nomadismo das comunidades da área de estudo, culminando na elaboração de um plano de gestão das suas necessidades, a fim de assegurar o preenchimento das lacunas existentes nos modelos de gestão sugeridos no presente estudo.

\section{REFERÊNCIAS}

[1] WRI - World Resources Institute - (2014) World's Last Intact Forests Are Becoming Increasingly Fragmented (Consult.15. Nov. 2015). Disponível em: WWW: <URL: http://www.wri.org/our-work/topics /forests.

[2] ONU - Organização das Nações Unidas (2014) - Mensagem do Secretário-Geral da ONU no Dia internacional da Floresta e da Árvore. (Consult.10/9/2015).Disponível em: <URL:http://www.plataformao ngd.pt/noticias/noticia.aspx? Id=834 ONU, 2014: http://www.plataformaongd.pt/noticias/noticia.aspx?id $=834$.

[3] FAO - Fundo das Nações Unidas para Agricultura e Florestas (2010a) - Global Forest Resources Assessment 2010. Main report. FAO Forestry Paper No. 163. Rome. (Consult. 20. Mai.2014). Disponível em: WWW: <URL: www.fao.org/docrep/013/i1757e/i1757e.pdf.

[4] Kissinger, G., M. Herold, V. De Sy (2012) - Drivers of Deforestation and Forest Degradation: A Synthesis Report for REDD+ Policymakers. Lexeme Consulting, Vancouver Canada.

[5] Mustalahti, I. (2011) - The Realities of Participatory Forest Management: Case Study Analyses from Tanzania, Mozambique, Laos and Vietnam, in: Footprints in forests. Efects and Impacts of Finish Forestry Assistance, Ministry for Foreign Afairs of Finland.

[6] Salomão, Alda e Matose, Frank (2007) - Towards community based forest management of miombo woodland in Mozambique.CBNRM.CIFOR.

[7] Sitoe, A., Salomão, A. e Wertz-Kanounnikoff, S. (2012) - O contexto de REDD+ em Moçambique: causas, actores e instituições. Publicação Ocasional 76. CIFOR, Bogor, Indonésia.

[8] Couple, S., Lewis, V., Ogutu, Z. \& Watson, C. (2002) - Living with Wildlife Sustainable - Livelihoods for Park - adjacente Communities in Kenya. London, UK: ITDG Publishing.

[9] Fabricius, C., Koch, E. \& Magome (2004) - Community Wildlife Management in Southern Africa: Challenging the Assumption of Eden. Evaluating Eden Series n ${ }^{\circ} 6$.

[10] Jones, B.T.B. \& Murpheree, M.W. (2004) - Community-Based Natural Resource Management as a Conservation Mechanism: Lessons and Directions. In Parks in Transition - Biodiversity, Rural Development and the Bottom Line, ed. B. Child, pp. 63 - 103. London, UK: Earthscan. 
[11] Katerere, Y. (2002) - Community-Public-Private Partnership in CBNRM: The Real Challenges? In: Proceedings from the International Symposium on Contested Resources: Challenges to Governance of Natural Resources in Southern Africa, Cape Town, 18 - 20 October 2000, eds. T.A. Benjaminsen, B. Cousins \& L. Thompson, pp. 20-38.

[12] Salomão, A. (2002) - Descentralização na gestão de Recursos Naturais. Aspectos legais e institucionais. In: Comunidades e Maneio Comunitário dos Recursos Naturais. Memórias da $2^{\text {a }}$ Conferência Nacional sobre o Maneio Comunitário dos Recursos Naturais, Maio de 2001, eds.E.Filimão e H. Massango, pp130 38). Maputo.

[13] Schackleton, S. \& Shkleton, C.C (2004) - Everyday Resources are valuable Enough for CommunityBased Natural Resource Management: Programme Suport: Evidence from South Africa. In: Rights, Resources \& Rural Development - Community - Based Natural Resource Management in Southern Africa, eds.C. Fabricius \& Koch, pp.235 -146. London, UK: Earthscan Publication in Rural Mozambique. $\mathrm{PhD}$ Thesis, Wageningen University.

[14] Turner, S. \& Meer, S. (2001) - Conservation by the People in South Africa: Findings from TRANSFORM Monitoring and Evaluation, 1999. South Africa: Programme for Land and Agrarian Studies, School of Government, University of the Western Cape.

[15] CDB - Convenção sobre a Diversidade Biológica (1992) - Hand book of Convention on Biological Diversity. 34 p $2^{\mathrm{a}}$ Edition.

[16] Forest Trends, Grupo Katoomba, e PNUMA (2008) - Pagamentos por Serviços Ambientais: Um Manual Sobre Como Iniciar. UNON/Publishing Services Section/Nairobi.

[17] Pagiola, S., Arcenas, A., Platais, G., 2005. Can Payment for Environmental Services Help Reduce Poverty? An Exploration of the Issues and the Evidence to Date from Latin America. World Development, Institutional arrangements for rural poverty reduction and resource conservation 33, 327-353.doi: 10.1016/j.worlddev. 2004.07.011.

[18] Jansen, P.C.M., Mendes, O. (1983-1994), Plantas medicinais: seu uso tradicional em Moçambique. Maputo: Ministério da Saúde, 4 vol. Johnstone, R., Cau, B., Norkof, S. (2004) - Legislação Florestal em Moçambique: Cumprimento e Impacto em Comunidades Residentes na Floresta. In: Comunidades e Maneio dos Recursos Naturais; Memórias da III Conferência Nacional sobre o Maneio Comunitário dos Recursos Naturais, Maputo, Volume I

[19] Porter, M.E. (1996) - Vantagem Competitiva. Rio de Janeiro: Campus.

[20] Godet, M.; Durance, P.; Dias, J. (2008) - A Prospectiva estratégica para as empresas e os territórios. IEESF, Lisboa.

[21] Ombe, A. Z. e Fungulane, A. (1996) - Alguns Aspectos da Conservação da Natureza em Moçambique, Editora Escolar, Maputo.

\section{AUTHOR'S BIOGRAPHY}

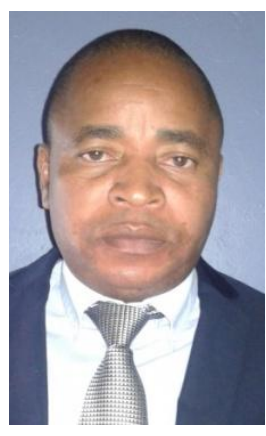

Jerónimo Victor Teixeira, Professor Auxiliar na Faculdade de Ciências da Terra e Ambiente da Universidade Pedagógica de Maputo, Moçambique.

Ph.D. em Geografia e Planeamento Territorial; Mestre em População e Desenvolvimento; Licenciado em Planificação, Gestão e Administração da Educação;Licenciado em Ensino de História e Geografia.

Citation: Jerónimo Victor Teixeira. " Opções Para Lidar Com as Causas de Desflorestamento no Norte de Moçambique: Caso Dos Distritos de Majune e Marrupa” International Journal of Humanities Social Sciences and Education (IJHSSE), vol 8, no. 2, 2021, pp. 166-173. doi: https://doi.org/10.20431/2349-0381.0802016.

Copyright: () 2021 Authors. This is an open-access article distributed under the terms of the Creative Commons Attribution License, which permits unrestricted use, distribution, and reproduction in any medium, provided the original author and source are credited. 